\title{
Erratum to: Surgical Endoscopy volume 21(12); volume 22(2)
}

\section{B. B. Agarwal}

Published online: 13 November 2009

(C) Springer Science+Business Media, LLC 2009

\section{Erratum to: Surg Endosc \\ DOI 10.1007/s00464-007-9320-y, \\ 10.1007/s00464-007-9435-1}

\section{Anatomical footprint for safe laparoscopic cholecystectomy without using any energy source: a modified technique}

10.1007/s00464-007-9320-y

B. Agarwal ${ }^{1}$, M. Gupta ${ }^{1}$, S. Agarwal ${ }^{2}$ and K. Mahajan ${ }^{1}$

${ }^{1}$ Department of General Surgery, Sir Ganga Ram Hospital, New Delhi, 110060, India

${ }^{2}$ Department of Anatomy, Lady Hardinge Medical College, New Delhi, 110001, India
Transaxillary endoscopic excision of benign breast lumps: a new technique

10.1007/s00464-007-9435-1

B. Agarwal ${ }^{1}$, S. Agarwal ${ }^{2}$, M. Gupta ${ }^{1}$ and K. Mahajan ${ }^{3}$

${ }^{1}$ Department of General Surgery, Sir Ganga Ram Hospital, New Delhi, 110060, India

${ }^{2}$ Department of Anatomy, Lady Hardinge Medical College, New Delhi, 110001, India

${ }^{3}$ Department of Academics and Research, Department of General Surgery, Sir Ganga Ram Hospital, New Delhi, 110060, India

The correct spelling of the first author in both articles is B. B. Agarwal. The first article was published in Volume 21 Number 12 and the second in Volume 22 Number 2.

The online version of the original article can be found under doi:10.1007/s00464-007-9320-y,10.1007/s00464-007-9435-1.

B. B. Agarwal ( $)$

Department of General Surgery, Sir Ganga Ram Hospital,

New Delhi 110060, India

e-mail: endosurgeon@gmail.com 